\title{
O PROCESSO DE CONSTRUÇÃO DE MATERIAL EDUCATIVO PARA MULHERES VÍTIMAS DE VIOLÊNCIA:
}

Márcia Schelb ${ }^{1}$

Maria Liz de Oliveira Cunha ${ }^{2}$

Leila Bernarda Donato Gottems ${ }^{1}$

Isabelle Patriciá Freitas Soares Chariglione ${ }^{2}$

\author{
https://orcid.org/0000-0003-1976-9138 \\ https://orcid.org/0000-0002-5945-1987 \\ https://orcid.org/0000-0002-2675-8085 \\ https://orcidorg/0000-0001-8627-3736
}

Objetivo: Descrever o processo de construção de um folder educativo sobre violência contra a mulher, destinada a promoção da saúde de mulheres. Metodologia: Pesquisa descritiva que utilizando o referencial da pesquisa-ação, a construção do folder contemplou quatro etapas: identificação do problema; preparação do conteúdo, baseado na literatura científica; construção gráfica do folder e revisão do material por pares. Resultados: O trabalho resultou na produção Discussão: A participação ativa dos profissionais e das mulheres vítimas de violência, com o uso de estratégia dialógica e coletiva, permeou o processo de construção do folder. As opiniões das mulheres e dos peritos, consideraram o folder como recurso adicional das atividades educativas, realizadas em serviços de atenção a mulher.

Conclusão: O folder é um suporte aos profissionais e às mulheres, nas dificuldades que permeiam o processo de reconhecimento da violência.

Descritores: Educação em saúde; Promoção de saúde; Enfermagem; Mulheres; Violência.

\section{THE PROCESS OF CONSTRUCTING EDUCATIONAL MATERIAL FOR WOMEN VICTIMS OF VIOLENCE}

Objective: Decrease the process of building an educational folder on violence against women, aimed at promoting the health of women. Methodology: Using the action research model, the folder construction included four steps: problem identification; content preparation, based on scientific literature; graphical construction of the folder and review of the material in pairs. Results: The work resulted in the production of the final version of the material in a folder format, entitled "Violence against women". Discussion: The active participation of professionals and women victims of violence, through the use of dialogic and collective strategies, permeated the process of building the folder. The opinions of women and experts, considered the folder as an additional resource of educational activities, held in any women's service. Conclusions: The folder is a support to professionals and women, in the difficulties that permeate the process of recognition of violence.

Descriptors: Health education; Health promotion; Nursing; Women; Violence.

\section{EL PROCESO DE CONSTRUCCIÓN DE MATERIAL EDUCATIVO PARA MUJERES VÍCTIMAS DE VIOLENCIA RESUMEN}

Objetivo: Decrever el proceso de construcción de un folder educativo sobre violencia contra la mujer, destinada a la promoción de la salud de las mujeres. Metodología: Utilizando el modelo de la investigación-acción, la construcción del folder contempló cuatro etapas: identificación del problema; preparación del contenido, basado en la literatura científica; construcción gráfica del folder y revisión del material por pares. Resultados: El trabajo resultó en la producción de la versión final del material en formato de un folder, titulado "Violencia contra la mujer". Discusión: La participación activa de los profesionales y de las mujeres víctimas de violencia, con el uso de estrategia dialógica y colectiva, permeó el proceso de construcción del folder. Las opiniones de las mujeres y de los expertos, consideraron el folder como recurso adicional de las actividades educativas, realizadas en cualquier servicio de atención a la mujer.Conclusão: El folder es un soporte a los profesionales ya las mujeres, en las dificultades que permean el proceso de reconocimiento de la violencia. Descriptores: Educación en salud; Promoción de la salud; enfermería; las mujeres; Violencia.

1Secretaria de Estado da Saúde do Distrito Federal

'Universidade Católica de Brasilia

Autor Correspondente: Isabelle Patriciá Freitas Soares Chariglione - Email:ichariglione@gmail.com 


\section{INTRODUÇÃO}

A violência contra as mulheres caracteriza-se por "qualquer ação ou conduta, baseada no gênero, que cause morte, dano ou sofrimento físico, sexual ou psicológico à mulher, tanto no âmbito público como no privado"1,2. Está presente em todo o mundo e atinge mulheres de todas as idades, classes sociais, raças e credos, com prejuízos psicológicos, físicos e sociais ${ }^{3}$. Os atos violentos ocorrem principalmente dentro do lar e são comumente praticados por alguém da família, em especial o próprio companheiro ${ }^{4.5}$. Devido a essa relação intima com o agressor ser tão frequente, a abordagem dos casos de violência contra a mulher requer atenção especial.

No cotidiano do trabalho com mulheres vítimas de queimaduras, muitos relatos apresentam-se suspeitos e até incompatíveis com a história acidental normalmente relatada. A exploração do tema "agressão" com as pacientes durante o atendimento médico em uma unidade de queimados mostrou-se delicado, pois envolve uma miscelânea de sentimentos. Muitas apresentam dificuldades em reconhecer a presença de comportamentos abusivos no ambiente doméstico e acabam por calar-se por medo, insegurança ou vergonha ${ }^{3}$.

No âmbito hospitalar, a ausência de suspeição por parte dos profissionais de saúde de que a queixa da paciente (muitas vezes inespecífica, mascarada ou incompatível) seja resultado de violência também contribui para a perpetuação da situação e a não orientação da paciente acerca do que fazer ${ }^{5-7}$.

Durante o processo de atendimento no Sistema Único de Saúde (SUS), a comunicação e a troca de informações, especialmente na questão da violência contra a mulher, é fundamental uma vez que todo o caminho do cuidado às paciente vítimas de abuso não depende exclusivamente de procedimentos e medicamentos, mas também do desenvolvimento de habilidades de prevenção, reconhecimento e enfrentamento das situações violentas ${ }^{7}$

Em todas as profissões de saúde existem como prática comum a construção e a utilização de materiais educativos. São consideradas ferramentas de grande utilidade e praticidade no intuito de informar e capacitar pessoas, uniformizar orientações e condutas e estimular a atuação profissional. Além disso, podem atuar tanto no público alvo quanto junto aos familiares e demais contatos sociais, ampliando a rede de informação e apoio 8.9 .
A produção e a oferta de informações sobre os direitos das pessoas, as medidas de prevenção e cuidado e os serviços disponíveis nas diversas estruturas do Estado por meio de materiais educativos tem sido apontadas como ferramentas importantes pelo Ministério da Saúde nos diferentes níveis de atenção ${ }^{10}$. Dentro dessa perspectiva, esses materiais constituem estratégia importantíssima para a promoção da saúde e o desenvolvimento de responsabilidades dos indivíduos e da coletividade ${ }^{11}$

A elaboração de material educativo segue um processo sistemático: identificação do problema, busca da literatura científica especializada e redação das informações selecionadas, propondo atividades e orientações que tenham como objetivo prevenir, recuperar, desenvolver ou reforçar atitudes e condutas com reflexos nas capacidades física, mental e social dos indivíduos ou da coletividade ${ }^{12,13}$.

A partir desse ponto, foi pensada uma maneira de se construir uma ferramenta que auxiliasse, de forma simples e rápida, tanto no diagnóstico da situação abusiva quanto na conduta a ser tomada. Portanto, a ideia para a elaboração desse material partiu da observação no serviço de que as mulheres vítimas de violência por queimadura relataram dificuldades para reconhecer as situações de abuso e de tomar atitudes após essa constatação. Este trabalho foi realizado considerando-se a importância desses aspectos e a ausência de um material educativo simples para as mulheres vítimas de violência no Distrito Federal, Brasil. Seguindo essa perspectiva, o estudo objetivou descrever as etapas envolvidas no processo de construção de um folder para mulheres que sofrem violência e são atendidas no SUS - DF.

\section{METODOLOGIA}

Para o desenvolvimento do folder, utilizou-se a pesquisa-ação como modelo. O principal pressuposto desse método é a construção do conhecimento de maneira coletiva e participativa, buscando identificar soluções para um problema que necessita ser estudado. A solução encontrada pode produzir reflexos positivos para as pessoas, a comunidade e a sociedade ${ }^{14}$

A "pesquisa-ação é um processo de interação entre pesquisadores e população interessada, para gerar possiveis soluções aos problemas detectados. Os resultados da pesquisa-ação se verificam nos modos de resolução de problemas concretos encontrados no decorrer 
da realização do projeto. A dimensão "participação" é fundamental em pesquisa-ação e em todos os métodos componentes das metodologias participativas ${ }^{14,15}$.

O processo contemplou cinco fases (Figura 1), conduzido no período de julho de 2017 a abril de 2018.

FIGURA 1 - O processo de construção do folder

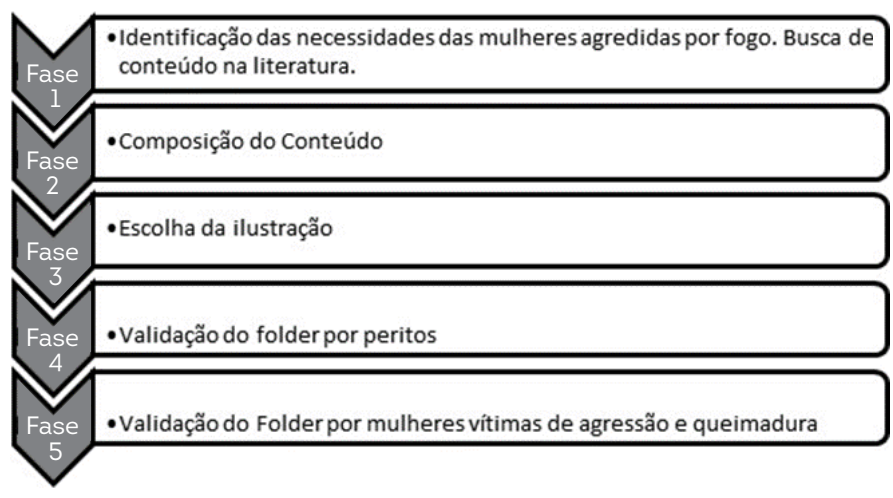

A primeira fase foi baseada nas necessidades das das mulheres agredidas por fogo. Esses dados foram obtidos quando os pesquisadores conduziram nove reuniões com o grupo de mulheres queimadas (entre julho de 2014 a julho de 2015). A coleta preliminar de dados aconteceu no setor ambulatorial de um hospital do DF. As mulheres foram convidados pela enfermeira a participar do grupo. Na primeira reunião, os participantes eram solicitados a expressar suas dúvidas e necessidades educacionais, bem como suas preferências em relação à forma de condução das reuniões. No final das reuniões, os participantes avaliavam os conteúdos abordados e os métodos educativos utilizados na reunião anterior. $O$ uso desses recursos permitiu a identificação das expectativas dos próprios participantes e promoveu a contribuição ativa na elaboração dos conteúdos e na escolha de estratégias a serem utilizadas na reunião seguinte. Todas as reuniões eram gravadas e transcritas literalmente. Esses dados transcritos foram utilizados para direcionar a elaboração dos tópicos do folder e de seus conteúdos principais (dúvidas e dificuldades) que referiam-se as necessidades apresentadas por essas mulheres.

$\mathrm{Na}$ elaboração do conteúdo (ainda na fase 1), foram realizadas pesquisas gerais e da literatura científica nos últimos 10 anos, para garantir a fidedignidade das informações. Foram utilizados termos como "violência contra as mulheres" e "violência doméstica", além da busca de textos relacionados à legislação pertinente.

$\mathrm{Na}$ segunda fase, livros e imagens de websites foram acessados para encontrar as melhores ilustrações. Imagens didáticas foram selecionadas e usadas como base para a elaboração das ilustrações por um profissional especializado. Algumas informações relacionadas a serviços públicos disponíveis às mulheres foram incluídas no folder, e a exatidão desses dados foi confirmada por telefone ou e-mail (fase 2).

$\mathrm{Na}$ terceira fase, o conteúdo preliminar foi desenvolvido com atenção dada à informação considerada essencial. Esse conteúdo foi submetido ao trabatho de edição e diagramação. As informações foram dispostas em folha única frente e verso e com duas dobras. Optou-se, considerando a sensibilidade das situações envolvidas no tema do folder, por não utilizar imagens reais nem estilizadas relacionadas com violência, incluindo apenas um desenho de capa que representasse a mulher e o feminino. $O$ critério estabelecido previamente para todo o processo de construção do folder, isto é, facilidade de leitura e clareza do conteúdo.

Após a conclusão gráfica do folder, este foi submetido para avaliação por pares, sendo estes dois médicos, dois enfermeiros e dois psicólogos (fase 4). Para cada tópico, os profissionais avaliaram a adequação e a apresentação das informações, considerando a perspectiva dos leitores. Em relação à linguagem, eles avaliaram coerência textual, conveniência na utilização das palavras, facilidade de compreensão e se os conceitos mais importantes foram abordados com vocabulário claro e objetivo. Os pares analisaram separadamente, apontaram os melhoramentos, e depois, conjuntamente trabalharam até a versão final com $100 \%$ de concordância para com o material produzido.

Na quinta fase, as mulheres vítimas de agressão por queimadura foram convidadas a participar do estudo, enquanto esperavam pela consulta para realização do curativo, no ambulatório do hospital de referencia do DF. Os critérios adotados para a inclusão das participantes foram: estar em acompanhamento pela plástica, ser alfabetizada, isto é, saber ler e escrever. Elas foram solicitadas a ler o folder e analisá-lo em termos de entendimento do vocabulário, bem como adequação das ilustrações (ilustração, ao padrão de cores e à distribuição das informações pelo corpo do folder, foram avaliados atratividade e organização do texto, adequação da composição visual características da ilustração de capa). Também foram solicitadas a indicar os termos estranhos ou difíceis, e a sugerir outros 
termos para substituição, que considerassem fáceis e compreensiveis.

No final da validação, esses profissionais forneceram opiniões gerais sobre o material (por meio de questionários disponibilizados para os mesmos) e suas recomendações foram integralmente aceitas e incorporadas, sendo relevantes destacar o cuidado desde as cores utilizadas até o tipo de linguagem utilizada para o público alvo. Posteriormente, a nova versão do folder foi submetida a outro processo de edição, revisão e diagramação.

O projeto da pesquisa foi aprovado pelo Comitê de Ética e Pesquisa parecer $\mathrm{n}$ ㅇ 1.504 .214 , sob o CAAE $\mathrm{n}$ 은 55002616.0.0000.5553. Todas as participantes do estudo assinaram o Termo de Consentimento Livre e Esclarecido (TCLE) após serem informadas sobre seus objetivos e procedimentos.

\section{RESULTADOS}

O estudo foi realizado por 13 colaboradoras, sendo 7 profissionais e 6 mulheres vítimas de violência. A equipe de profissionais foi composta por duas enfermeiras , dois médicos cirurgião plástico e oftalmologista, uma psicóloga, uma técnica de enfermagem e um enfermeiro com experiência em promoção da saúde. Seis deles tinham o título de especialista, dois mestrandos e três tinham doutorado. Sete estavam trabalhando em uma Unidade de Saúde (US), três eram professores e pesquisadores. Foram contratados para a execução do projeto gráfico do folder um profissional da comunicação e um desenhista.

As mulheres tinham entre 25 e 35 anos de idade. As ocupações destas eram: estudantes (3), do lar (2), caixa de supermercado (1) e desempregada (1). A escolaridade variou entre o primeiro grau e o ensino superior

O folder era composto por uma folha A4, com informações em frente e verso e duas dobraduras, constituindo seis nichos. Com as respectivas dobras e após a abertura, os espaços apresentaram-se na seguinte sequência: capa, desenvolvimento (composto por quatro partes) e a contracapa.

A primeira versão do folder estava impresso nas cores verde e laranja. No processo de validação por peritos, as sugestões relacionadas à cor, ilustração, informação, à linguagem e ao vocabulário foram fornecidas. As principais sugestões dos peritos para a inclusão de informações estão indicadas na Quadro 1.
Quadro 1 - Sugestões feitas por peritos para inclusão de informações no folder.

\begin{tabular}{|l|l|}
\hline \multicolumn{1}{|c|}{ Assunto } & \multicolumn{1}{c|}{ Sugestão } \\
\hline \multirow{4}{*}{ Cores } & Lilás e roxo pois são as cores do feminino \\
\cline { 2 - 2 } & Roxo e vermelho \\
\hline \multirow{3}{*}{ Ilustração } & $\begin{array}{l}\text { Colocar um desenho artístico sem usar } \\
\text { imagens da internet. }\end{array}$ \\
\cline { 2 - 2 } & Não pegar da internet a ilustração \\
\hline \multirow{3}{*}{ Informação } & Relacionar outras formas de violência \\
\cline { 2 - 2 } & Colocar o site da mulher do GDF \\
\cline { 2 - 2 } & $\begin{array}{l}\text { Colocar o telefone da delegacia de } \\
\text { atendimento a mulher de Brasília }\end{array}$ \\
\hline
\end{tabular}

As sugestões foram incluidas e submetidas às equipes editorial, de diagramação e de arte-final. Para a capa, a partir das orientações fornecidas pelos peritos, foi produzida uma figura artística de traços fluidos representando o rosto de uma mulher de perfil (Figura 2). O padrão de cores do folder foi escolhido dentro dos matizes do lilás e do rosa, em referência ao feminino e às políticas públicas relacionadas ao tema, remetendo como metáfora às marcas da violência no corpo das mulheres ${ }^{16}$.

FIGURA 2 - Folder - Violência contra a mulher (Face 1)

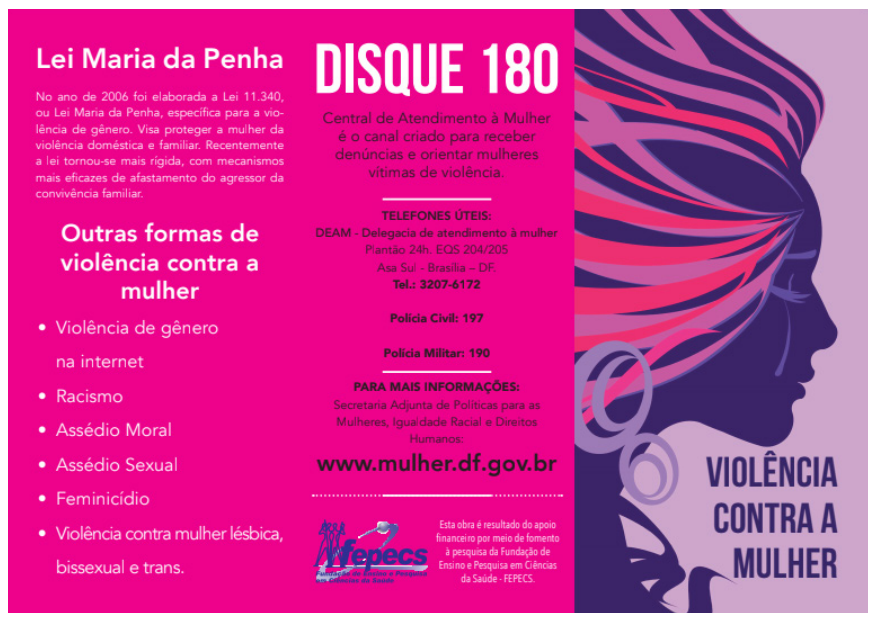

Todos os peritos fizeram avaliação positiva do folder. A linguagem foi considerada fácil para o entendimento e esse aspecto foi destacado como vital para promover os interesses das mulheres agredidas.

Em relação ao conteúdo, as informações foram dispostas na sequência em que seriam utilizadas pelo leitor. Inicialmente foram incluídas definições básicas sobre os tipos de violência, em linguagem coloquial: violências física, psicológica, sexual, moral e patrimonial.

A partir de então, foi incluído um pequeno questionário, em linguagem de simples acesso e mimetizando uma conversa, onde a marcação de apenas um item já indicaria a existência de situação de abuso na relação familiar. 
No desenvolvimento, os quatros espaços do folder, foram preenchidos com as informações consideradas pertinentes ao tema, obtidas a partir da bibliografia consultada. A primeira página do folder, também chamada de página interna, contém as três primeiras partes do desenvolvimento.

Na primeira parte foi feito um resumo do que seria a "violência contra as mulheres" e os tipos de violências (Figura 3). Como era necessário passar a mensagem adequada e sem dupla interpretação, a linguagem utilizada foi a mais coloquial possivel sem, no entanto, excluir alguns termos mais complexos fundamentais para o entendimento das definições apresentadas.

$\mathrm{Na}$ segunda parte do desenvolvimento (Figura 3), com o intuito de simplificar ainda mais a compreensão das informações, foram feitas exemplificações sobre o que seriam as formas de violência, além das agressões físicas e das sexuais (as mais conhecidas), como xingamentos, humilhações, ameaças, restrição da liberdade, destruição ou subtração de bens, entre outros. A distribuição dessas informações foi feita a partir de uma sequência de informações onde a leitora poderia assinalar um ou mais itens, auxiliando no diagnóstico da existência de uma situação de abuso ou violência em seu meio.

Na terceira parte (Figura 3) são apresentadas as condutas a serem tomadas em caso de o leitor enquadrar a situação em questão dentro de alguma forma de violência. Essas condutas abrangem tanto a mulher quanto os filhos e sugerem o que fazer em caso de emergências, contendo também os contatos de órgãos do governo relacionados à prevenção, condução e combate à violência contra as mulheres e a capa.

Na quarta parte do desenvolvimento, são apresentadas informações sobre a Lei Maria da Penha, de maneira simples e resumida, como mecanismo de proteção da mulher frente à violência doméstica. Em seguida são citadas outras formas de violência contra a mulher, que podem ou não estar relacionadas ao convívio doméstico, como o assédio moral e sexual, o feminicidio e a violência contra a mulher lésbica, e transexual.

Por fim, são apresentados os números de telefones e site de órgãos do Estado responsáveis pelo atendimento de emergência das mulheres em situação de violência doméstica, com destaque para a DEAM (Delegacia de Atendimento à Mulher).
FIGURA 3 - Folder - Violência contra a mulher (Face 2)

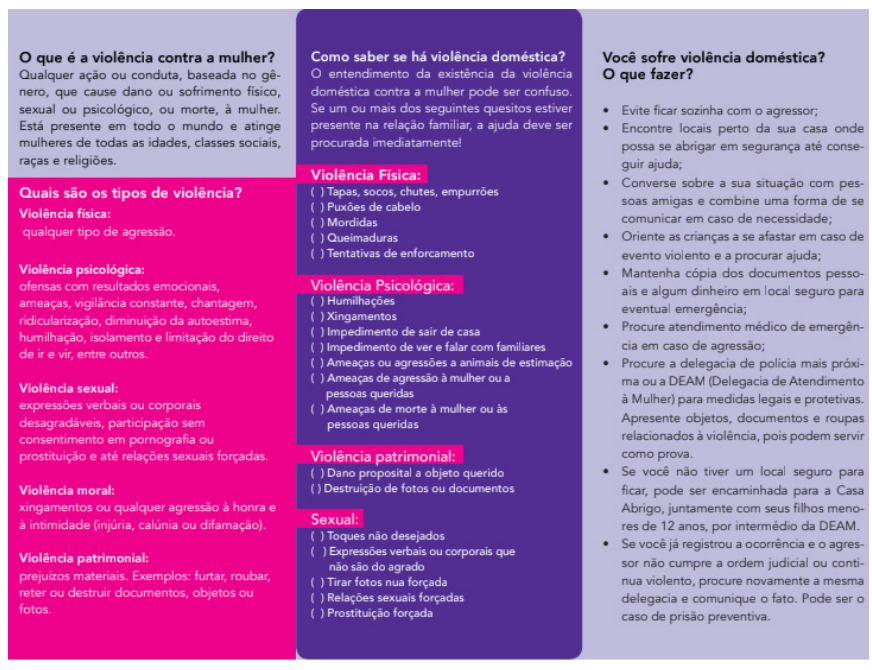

\section{DISCUSSÃO}

A violência contra as mulheres é um dos temas que mais preocupa as análises sobre o feminino e tem sido objeto de cada vez mais estudos e programas de governo. Apesar de ser uma questão muito presente no cotidiano, mostra-se subavaliada nos serviços de saúde, onde representa causa associada em importante parcela dos atendimentos hospitalares ${ }^{7}$

Dentre as estratégias, considera-se que o acesso à informação é uma das ações fundamentais para o empoderamento, a autonomia e o protagonismo das pessoas, tanto pacientes quanto profissionais e gestores, dentro do sistema de saúde ${ }^{11}$. Nesse sentido, o processo de construção de recursos educativos, é recomendada a interação entre as pessoas envolvidas ${ }^{17}$. Essa interação, associada ao comprometimento da participação para a educação em saúde, é premissa importante da metodologia da pesquisa-ação.

A utilização e construção de materiais educativos impressos da área da saúde é prática comum no SUS e representa ferramenta indispensável para compartilhamento de conhecimento e uniformização de condu$\operatorname{tas}^{10,11}$. Manuais de cuidado em saúde, folders e cartilhas, por exemplo, são capazes de promover resultados expressivos para os participantes das atividades educativas $^{18}$.

Para a construção de materiais educativos, deve-se sempre ter em mente a otimização do acesso à informação, como linguagem de fácil compreensão e recursos de imagem, facilitando a comunicação entre emis- 
sor e receptor. O material precisa ser também atrativo, despertando o interesse na leitura e estimulando a compreensão do texto ${ }^{19}$. Em consonância, neste estudo, observou-se que o material educativo elaborado se apresenta de fácil entendimento e com informações importantes que permitem o reconhecimento rápido das situações de violência contra a mulher, principalmente a doméstica, ao mesmo tempo em que orienta de forma objetiva o que fazer a partir dessa constatação. A avaliação do folder pelas mulheres que viveram a violência demonstrou que seu conteúdo foi escrito de acordo com a realidade de vida delas, considerando-se a avaliação positiva que fizeram do material.

As atividades dos profissionais de saúde tornam-se mais ricas com a incorporação de materiais educativos, marcando a importância prática dos assuntos abordados, e facilitando o processo de orientação em saúde. Como as mulheres vítimas de algum tipo de violência procuram mais os serviços de saúde, muitas vezes omitindo as situações pelas quais estão passando, os materiais educativos aparecem como ferramentas importantes na atuação prática dos profissionais relacionados ao atendimento ${ }^{2}$. Representam fontes rápidas de orientação e conduta frente ao problema, unificando a linguagem, bem como proporcionando a integralidade e a multidisciplinaridade do cuidado, conforme preconiza o SUS 11,12

A comunicação adequada, clara e acolhedora, dos profissionais de saúde entre si e entre esses e a comunidade atendida, proporciona melhores resultados nos atendimentos ${ }^{20-22}$. Nesse sentido, o folder produzido neste trabalho representa importante instrumento de interação entre os atores dentro do processo de atendimento à mulher vítima de violência, possibilitando de modo objetivo a transmissão de informações.

Não podemos negar a existência de inúmeros folders sobre o tema o que constitui um fator limitante, porém, não evidenciamos na literatura artigos que relatem a construção de um folder como o método usado nesta prática. O perfil destas mulheres vítimas de violência por fogo, adultas e jovens não influenciou no conteúdo do folder. Este foi concebido para todo e qualquer tipo de violência, não apareceu uma especificidade alusiva ao fogo, mesmo sendo estas participantes vítimas deste tipo de violência.

\section{CONCLUSÃO}

A principal proposta da criação deste folder foi a de ampliar o potencial da da mulher vítima de violência e da sua família, e promover a condição de saúde. O folder é um suporte aos profissionais e às mulheres, para que superem dúvidas e dificuldades que permeiam o processo de reconhecimento da violência.

A versão online destea folder está disponível ao público no site da FEPECS (https://mestradoprofescs.wixsite. com/mestradoprofissional) é importante para o acesso dos leitores, mas não é suficiente para representar como recurso amplamente utilizado pelos usuários do SUS, tornando-se necessário disponibilizá-la na versão impressa para as instituições públicas de saúde.

FINANCIAMENTO: Fundação de Ensino e Pesquisa do Distrito Federal - FEPECS.

\section{REFERÊNCIAS}

1. Organização dos Estados Americanos. Comissão Interamericana de Direitos Humanos. Convenção interamericana para prevenir, punir e erradicar a violência contra a mulher [Internet]. Belém do Pará, 1994 [acesso em 06 ago 2016]. Disponivel em: http://www. cidh.org/Basicos/Portugues/m.Belem.do.Para.htm

2. Cordeiro N. Ação governamental e direitos das mulheres: abrigamento para mulheres ameaçadas de morte no Brasil. Rev. Bras. Ciênc. Polit. [online]. 2017, n.23 [cited 2018-11-18], pp.259294. Disponivel em: http://www.scielo.br/scielo.php?script=sci_ arttext\&pid=S0103-33522017000200259\&lng=en\&nrm=iso. ISSN 2178-4884. http://dx.doi.org/10.1590/0103-335220172308.

3. Osis MJD, Duarte GA, Faúndes A. Violência entre usuárias de unidade de saúde: prevalência, perspectiva e conduta de gestores e profissionais. Rev Saúde Pública [Internet]. 2012 [acesso em 05 ago 2017]; 46(2): 351-8. Disponivel em: http://www.scielo.br/scielo. php?script=sci_arttextEpid=S0034-89102012000200018.

4. Garcia MV, Ribeiro LA, Jorge MT, Pereira GR, Resende AP. Caracterização dos casos de violência contra a mulher atendidos em três serviços na cidade de Uberlândia, Minas Gerais, Brasil. Cad Saúde Pública [Internet]. 2008 [acesso em 06 de agosto de 2015]; 24(11): 2551-63. Disponivel em: http://www.scielo.br/pdf/csp/ v24n11/10.pdf.

5. Paiva LML; Sabadell AL. O crime de estupro à luz da epistemologia feminista: um estudo de casos no stf. DELICTAE: Revista de Estudos Interdisciplinares sobre o Delito, [S.l.], v. 3, n. 4, p. 110-155, jul. 2018 ISSN 2526-5180. Disponivel em: <http://delictae.com.br/index. php/revista/article/view/64>. Acesso em: 18 nov. 2018.https://doi. org/10.24861/2526-5180.v3i4.64. 
6. Signorelli MC, Auad D, Pereira PPG. Violência doméstica contra mulheres e a atuação profissional na atenção primária à saúde: um estudo etnográfico em Matinhos, Paraná, Brasil. Cad. Saúde Pública [Internet]. 2013 [acesso em 17 out 2018]; 29(6): 1230-40. Disponível em: https://www.scielosp.org/scielo. php?pid=S0102-311X2013001000019\&script=sci_arttext.

7. Pedrosa CM, Spink MJP. A violência contra mulher no cotidiano dos serviços de saúde: desafios para a formação médica. Saude Soc. [Internet]. 2011 [acesso 02 nov 2018] 20(1): 124-35. Disponivel em: https://www.scielosp.org/scielo. php?pid=s0104-12902011000100015\&script=sci_arttext.

8. Pimentel PP. Toldrá RC. Desenvolvimento de manual para orientações básicas do dia a dia para pessoas com esclerose múltipla. Cad Ter Ocup UFSCar [Internet]. 2017 [acesso 23 out 2018]; 25(1): 67-74. Disponivel em: http://www. cadernosdeterapiaocupacional.ufscar.br/index.php/cadernos/ article/viewFile/1483/815

9. Oliveira, MLC. Vozes em sintonia: Educação Popular sobre DST via rádio comunitária. Interface (Botucatu) [online]. 2014, vol.18, suppl.2 [cited 2018-11-18], pp.1523-1528. Disponivel em: http:// www.scielo.br/scielo.php?script=sci_arttext\&pid=S141432832014000601523 \&lng=enEnrm=iso. ISSN $1414-3283$. http://dx.doi.org/10.1590/1807-57622013.0567.

10. Ministério da Saúde (BR). Portaria nㅇ 793, de 24 de abril de 2012. Institui a Rede de Cuidados à Pessoa com Deficiência no âmbito do Sistema Único de Saúde. Diário Oficial da União [Internet]. $\quad 25$ abr 2012 [acesso 19 out 2018]; Seção 1. Disponivel em: http://bvsms.saude.gov.br/bvs/saudelegis/ gm/2012/prt0793_24_04_2012.html.

11.. Ministério da Saúde (BR). Secretaria de Vigilância à Saúde. Secretaria de Atenção à Saúde. Política Nacional de Promoção da Saúde: PNaPS: revisão da Portaria MS/ GM nㅇ 687, de 30 de março de 2006 [Internet]. Brasilia, 2014 [acesso 19 out 2018]. Disponivel em: http://bvsms.saude.gov.br/bvs/publicacoes/ politica_nacional_promocao_saude_pnaps.pdf.

12. Zombini EV, Pelicioni MCF. Estratégias para a avaliação de um material educativo em saúde ocular. Rev. Bras. Crescimento Desenvolvimento Hum [Internet]. 2011 [acesso 19 out 2018]; 21(1): 51-8. Disponivel em: http://www.journals.usp.br/jhgd/ article/view/19995/22081.

13. Lima ACMACC, Bezerra KC, Sousa DMN, Rocha JF, Oriá MOB. Construção e Validação de cartilha para

prevenção da transmissão vertical do HIV. Acta Paul Enferm [Internet]. 2017 [acesso 01 nov 2018]; 30(2):181-9. Disponivel em: http://www.scielo.br/scielo.php?pid=s010321002017000200181 \&script=sci_arttext.

14. Thiollent M. Metodologia da pesquisa-ação. 14ạ ed. São Paulo: Cortez; 2005
15. Thiollent, M.; Silva MG. Metodologia de pesquisa-ação na área de gestão de problemas ambientais RECIIS, v.1, n.1, p.93$100,2007$.

16. Daron, VLP. Um grito lilás: cartografia da violência às mulheres do campo e da floresta. Brasilia: Secretaria de Politicas para as Mulheres [Internet]. 2009 [acesso 01 nov 2018]. Disponivel em: http://www.spm.gov.br/arquivosdiversos/sev/coordenacao-geral-de-acoes-preventivas-egarantia-de-direitos/enfrentamento-a-violencia-contraas-mulheres-do-campo-e-da-floresta/documentos/um\%20 grito\%20lilas.pdf/@@download/file/um\%20grito\%20lilas.pdf.

17. Carvalho, M.A.P. Construção compartilhada do conhecimento: análise da produção de material educativo. In: BRASIL. Ministério da Saúde. Secretaria de Gestão Estratégica e Participativa. Caderno de Educação Popular e Saúde. Brasilia: Ministério da Saúde, 2007. p.91-102.

18. Reberte LM, Hoga LAK, Gomes ALZ. O processo de construção de material educativo para a promoção da saúde da gestante. Rev Latino-Am Enfermagem [Internet]. 2012 [acesso 03 nov 2018]; 20(1):[8 telas]. Disponivel em: http://www. scielo.br/pdf/rlae/v20nl/pt_14.

19. Castro ANP, Lima Júnior EM. Desenvolvimento e validação de cartilha para pacientes vítimas de queimaduras. Rev Bras Queimaduras [Internet]. 2014 [acesso 03 nov 2018]; 13(2): 103-13. Disponivel em: http://rbqueimaduras.org.br/content/ imagebank/pdf/v13n2.pdf\#page=55.

20. Coriolano-Marinus MWL, Queiroga BAM, Ruiz-Moreno L, Lima LS. Comunicação nas práticas em saúde: revisão integrativa da literatura. Saúde Soc São Paulo [Internet]. 2014 [acesso 07 nov 2018]; 23(4): 1356-69. Disponivel em:http://www. scielo.br/pdf/sausoc/v23n4/0104-1290-sausoc-23-4-1356. pdf.

21. Oliveira L, Leal S. (2016). Mulheres em situação de violência a que buscaram apoio no Centro de Referência Geny Lehnen/RS. Enfermagem em Foco, 7(2). [acesso 14 jun 2019]. Disponivel em: http://revista.cofen.gov.br/index.php/enfermagem/article/ view/800/325.https://doi.org/10.21675/2357-707X.2016. v7.n2.800

22. André SR et al. Responsabilidade técnica em enfermagem: conhecendo sua importância para o exercicio profissional. Enfermagem em Foco, [S.l.], v. 10, n. 1, fev. 2019. ISSN 2357-707X. [acesso 14 jun 2019]. Disponivel em: http://revista.cofen.gov.br/index.php/enfermagem/article/ view/1512/492. https://doi.org/10.21675/2357-707X.2019.v10. $\mathrm{n} 1.1512$.

RECEBIDO: 16/05/2019

ACEITO: 08/07/2019 